\title{
LEGITIMACY JUDGMENTS ABOUT CORPORATE TAX AVOIDANCE: A DELIBERATION EXPERIMENT
}

\author{
ROBIN SCHNIDER \\ Department of Business Administration \\ University of Zurich \\ Universitätsstrasse 84 \\ 8006 Zurich, Switzerland \\ PATRICK HAACK \\ University of Lausanne, Switzerland \\ ANDREAS GEORG SCHERER \\ University of Zurich, Switzerland
}

\section{INTRODUCTION}

The success or failure of multinational corporations (MNCs) can depend on a single factor: social acceptance or legitimacy. This is most evident in cases of corporate scandals such as the Volkswagen diesel exhaust system scandal in 2015 or the BP oil spill in the Gulf of Mexico in 2010. In order to repair or maintain legitimacy, organizational research suggests that corporations need to engage in deliberations with stakeholders and civil society groups (Scherer \& Palazzo, 2007, 2011; Scherer, Palazzo, \& Seidl, 2013). Deliberation in this context is understood as "debate and discussion aimed at producing reasonable, well-informed opinions in which participants are willing to revise preferences in light of discussion, new information, and claims made by fellow participants" (Chambers, 2003: 309). To test whether entering deliberation may serve as a legitimation strategy for a firm, and likewise as a delegitimation strategy for an NGO criticizing a business, we conducted an experiment with 293 participants at the University of Zurich in Switzerland, featuring face-to-face deliberations with real firm and NGO representatives.

In our experiment, participants were asked to discuss a controversial business practice in small groups, either with or without real representatives of the business and/or its critics. To measure the effects of deliberation we assessed participants' legitimacy judgments about both a controversial business practice and the organization's engagement in such a practice, separately, before and after the discussion. To identify the effects of representatives on legitimacy, we used a difference-in-differences design (see e.g., Antonakis, Bendahan, Jacquart, \& Lalive, 2010), comparing the changes in perceived legitimacy across randomly assigned treatment groups.

As context for the deliberations in our experiment, we chose the topic of corporate tax avoidance (Avi-Yonah, 2014; Dharmapala, 2014; Hanlon \& Heitzman, 2010) and the facilitating role of the four largest auditing and tax accounting firms - Deloitte, EY, PwC, and KPMG commonly referred to as the "Big Four" (Addison \& Mueller, 2015; Sikka \& Willmott, 2013). In our study, the Big Four were represented by employees of a Big Four firm and the critics of tax avoidance and the Big Four were represented by members of a non-governmental organization (NGO) specializing in social issues.

This context not only seemed ideal for methodological reasons, as we explain in the paper, but the topic itself deserves attention by management research, given that tax base erosion 
has been addressed as one of the grand challenges for societies by the OECD (2013) and the United Nations (2015) and has become a matter of public concern (e.g., BBC, 2012; Hodge, 2016). Corporate tax avoidance can be defined as the corporate practice of applying legal means or exploiting of tax loopholes to reduce the amount of tax payable by a corporation (Dowling, 2014; Prebble \& Prebble, 2009). This practice has come under increasing public scrutiny following widely publicized media reports about several MNCs that paid hardly any taxes (e.g., BBC, 2012; Hodge, 2016). Also the role of the Big Four tax accounting firms has been critically addressed by several news outlets, especially in the UK and Australia, referring to them as facilitators, enablers, or even "masterminds" of global tax avoidance (ABC News, 2016). Such media reports have portrayed the Big Four as the architects of tax schemes that cost governments and taxpayers more than US \$1 trillion a year (e.g., West, 2016), with US \$160 billion in the US alone (Zucman, 2015).

The results of our study suggest that entering deliberations can indeed be a valid legitimation strategy for a firm and can offer an effective delegitimation strategy for an NGO critical of a firm and its activities. However, merely entering deliberative processes may not be sufficient for organizational actors to affect legitimacy, as the relative performance of the two types of representatives (firm vs. NGO) in terms of convincing arguments was found to determine the direction and size of the effect. That is, the engagement of firm representatives in deliberation only led to legitimation if their arguments were perceived as more convincing than those of the critical NGO representatives, whereas there was delegitimation if the opposite was the case. Furthermore, our findings show that participants judged the legitimacy of tax avoidance separately from the legitimacy of the tax accounting firm involved in this practice. While firm representatives mainly affected the perceived legitimacy of their organization, the NGO representatives and their arguments were more relevant for the perceived legitimacy of the tax avoidance practice.

Overall, our study offers three important contributions to management research. Phenomenologically, it sheds light on tax avoidance as a largely underexplored topic in management research. Methodologically, it tests the causal effects of deliberation on legitimacy perceptions through a novel experimental design for deliberation research. Finally, theoretically, it conceptualizes legitimacy as an interactive and communicative process of making judgments.

\section{THEORY AND HYPOTHESES}

Following deliberative theory, deliberation participants test their views in the deliberative process based on the quality of exchanged arguments (e.g., Habermas, 1996; Manin, 1987). Along this line of reasoning, the arguments of firm and NGO representatives can be expected to particularly affect the legitimacy judgements of deliberation participants. As the representatives possess expert knowledge about the case, their arguments can be expected to be sophisticated.

We focus on the "marginal effect" of representatives on perceived legitimacy - meaning the effect of deliberating with either a firm or a NGO representative or both in comparison to deliberating without a representative (baseline). For a firm (NGO) representative, we expect a positive (negative) marginal effect, such that the change in perceived legitimacy of an organization and its actions should be more positive (negative) when a firm (NGO) representative takes part in deliberation compared to a setting without such a representative. If both types of representatives are present, deliberative theory would suggest that the direction of the effect on legitimacy depends on whose arguments are perceived to be more convincing. 
We further argue that it is important to distinguish analytically between the legitimacy of an entity and the legitimacy of its actions. While the legitimacy of an organization is arguably related to the legitimacy of its actions, it is possible that they are assessed separately and are mentally represented as different objects of legitimacy (Johnson, 2004). As firm and NGO representatives differ in what they are representing and typically also in their argumentation regarding the relationship between the organization and a controversial practice, they are likely to affect judgments about the two objects of legitimacy differently. Specifically, we expect firm (NGO) representatives to have a relatively stronger impact on the perceived legitimacy of the organization (practice).

\section{EXPERIMENTAL DESIGN}

The experiment was conducted in January 2017 at the University of Zurich in Switzerland with a total of 293 participants (165 male, 128 female), which were mainly students with a mean age of 25.3 years. We ran a total of ten experimental sessions that lasted 105 minutes each, for which participants were reimbursed the equivalent of 80 USD.

\section{Study Procedure}

The experiment consisted of two parts. In the first part, all participants of an experimental session were welcomed and instructed in the same room, where they received information material on the topic (global tax avoidance and the role of the Big Four) and after reading the material filled out an initial questionnaire. During the second part, the participants discussed three open questions included in the information material in small groups of seven in separate rooms (different treatments) for 45 minutes, and subsequently, answered a second questionnaire. Upon completion of the questionnaire, they were directed to the payout station to receive their payment.

The discussion and treatment groups were randomly assigned at the beginning of the experiment by having participants pick cards with imprinted room numbers that determined which room they would participate in for the second part of the experiment.

\section{Treatment Groups}

There were five different simultaneous treatment groups (i.e., rooms) in each session: control condition, firm condition, NGO condition, mixed condition, and wait condition.

In the "control condition", the group of seven participants was not joined by an expert for the discussion. In the "firm condition", the group was joined by a representative of the Big Four (a corporate tax specialist working for a Big Four firm that collaborated with us for the experimental study). In the "NGO condition", the group was joined by a representative of the critics of the Big Four (a member of a Swiss NGO that is critical of tax avoidance and the Big Four). In the "mixed condition", the group was joined by both a representative of the Big Four and a representative of its critics. The "wait condition" was a treatment without discussion, where participants simply waited for 45 minutes in a separate room before filling out the second questionnaire. This additional treatment allowed us to check whether the passage of time alone (as opposed to deliberation) would lead to changes in opinion. 


\section{Form of Discussion}

Each discussion group was joined by a neutral moderator (research assistants at the department of business administration of our home university) to manage the process of discussion and to ensure that the rules of the discussion were adhered to. The rules were based on those applied in deliberative polling (cf. Fishkin \& Luskin, 2005) and the discussion was led as an essentially free conversation among the participants, whereby the moderator managed the time, opened and closed the discussion questions included in the information material, and made sure that no one participant either dominated the conversation or refrained from talking entirely.

To incorporate the firm and NGO representatives in the discussion in the corresponding treatments, they were introduced by the moderator and were asked to make an introductory statement of 1.5-2 minutes for each question. If two experts were present, both made an introductory statement for each question in alternating order (between questions). To ensure that the content was more or less the same within a group of representatives, they were asked to prepare common introductory statements and to discuss the questions listed in the information material with their team ahead of time so as to agree on a joint line of argumentation.

Since the participants' discussions in the different treatment groups were held simultaneously, at least two representatives of the Big Four and two NGO representatives needed to be available. The representatives switched treatments between sessions to counterbalance potential confounding effects resulting from individual differences.

\section{Dependent Variables}

Legitimacy. To assess our main dependent variables, the perceived legitimacy of the Big Four and of corporate tax avoidance, we constructed our own legitimacy scale. We formulated a series of items in relation to the three dimensions of legitimacy as identified by Suchman (1995) - pragmatic legitimacy (Is it beneficial?), cognitive legitimacy (Is it taken for granted?), and moral legitimacy (Is it the right thing to do?) - and tested them in an online survey. All final items ( 31 in total) were rated on an 11-point Likert scale $(-5=$ totally disagree, $0=$ neither agree nor disagree, $+5=$ totally agree) and then combined into a single measure as a weighted average. The weights of different legitimacy dimensions were determined by their explanatory power on a measure for the "overall legitimacy" of the practice or the organization, a compound measure of the participants' indicated agreement with the two items "I think [tax avoidance is/the Big Four and their actions are] legitimate and appropriate" and "I think [tax avoidance is/the Big Four and their actions are] illegitimate and inappropriate."

Explicit Changes in Legitimacy. In addition to comparing the changes in the abovedescribed legitimacy scale before and after the discussions, we also wanted a more explicit measure of changes in participants' legitimacy judgments. Therefore, in the second questionnaire, we asked participants to indicate whether their opinion regarding tax avoidance or the Big Four had changed during the discussion and to what extent, again using an 11-point scale $(-5=$ worse, $0=$ same, $+5=$ improved $)$.

\section{Control Measures}

Besides individual characteristics and ratings of the representatives, one of the crucial control measures to test our hypotheses concerned the relative performance of representatives in 
the mixed condition, in terms of the persuasiveness of their arguments. Accordingly, participants in the mixed condition (where both types of representatives were present) were asked in the second questionnaire, "Whose arguments were more convincing, those of the employee of [name of the company] (Big Four) or those of the member of [name of the NGO] (critics)?" This question was rated on an 11-point scale $(0=\mathrm{NGO}, 5=$ both equally, $10=$ Big Four $)$.

\section{RESULTS}

We tested our hypotheses by comparing the treatment effects on changes in legitimacy to the control condition (= baseline). Figure 1 shows these marginal effects of the different treatment groups for our two measures of changes in legitimacy (implicit measure via legitimacy scale and explicit measure via direct question about change in opinion). In line with our hypotheses, the presence of a firm (NGO) representative in the firm (NGO) condition tends to lead not only to more positive (negative) changes in legitimacy compared to the control condition - i.e., a positive (negative) marginal effect, as can be seen in Figure 1 -, but also to an overall increase (decrease) in perceived legitimacy. The pattern in the mixed condition, as expected, critically hinged on which representative was perceived as more convincing. Accordingly, the effects of the mixed condition do not significantly differ from those of the firm condition for the participants who perceived the arguments of the firm representative as relatively more convincing ("mixed adv. firm"). Analogously, the effects of the NGO condition are in line with the observed changes for participants in the mixed condition who perceived the NGO representative as more convincing ("mixed adv. NGO"). For participants who perceived both representatives as equally convincing ("mixed tie"), the results did not significantly differ from the control condition.

Regarding the relative impact of representatives on the perceived legitimacy of the practice vs. the organization, it turned out that the firm representatives indeed had a relatively stronger impact on the perception of the organization than on that of the practice and that the reverse was true for the NGO representatives. In fact, Figure 1 shows that by comparing the relative sizes of the two bars (organization vs. practice) for the respective treatments, the firm representatives mainly affected the perceived legitimacy of the organization (i.e., the Big Four), while they had less of an effect on the perceived legitimacy of the practice (i.e., tax avoidance). The NGO representatives, in contrast, significantly affected the perceived legitimacy of the practice, but not the legitimacy of the organization. The relative importance of representatives is also evident in the mixed condition as a whole, whereby the marginal effect on the organization tends to be positive and the marginal effect on the practice tends to be negative.

We found that these main effects and findings were also robust when controlling for exogenous differences, unrelated to deliberation, such as individual differences between participants. Therefore, we conclude that the treatment effects are endogenous and indeed depend on the process of deliberation.

Figure 1 about here 


\section{DISCUSSION}

By conducting a deliberation experiment with actual firm and NGO representatives in the context of tax avoidance, we demonstrated that entering deliberation can offer a valid legitimation strategy for a firm or an effective delegitimation strategy for an NGO, respectively. The direction as well as the size of deliberative effects, however, is contingent on the (relative) persuasiveness of arguments used in such deliberations. Moreover, our results suggest that the perception of a practice and an organization engaging in it are partly separable and can also be affected differently by deliberation. If generalizable, our findings would imply that firms should only enter public deliberation for legitimation purposes, if their organization itself is being criticized, and should not when only a practice they are involved in is publically contested. In contrast, NGOs should only engage in deliberation if they are trying to delegitimize a practice, rather than an organization.

Although we established a significant causal relationship between deliberation and legitimation, this is only the first step in empirically investigating whether entering deliberative processes may indeed serve as a (de-)legitimation strategy for organizations in real-world scenarios. Our methodology and findings enable interesting avenues for future research.

\section{REFERENCES AVAILABLE FROM THE AUTHORS}

Figure 1: Marginal Treatment Effects for Implicit and Explicit Measure of Legitimacy Changes

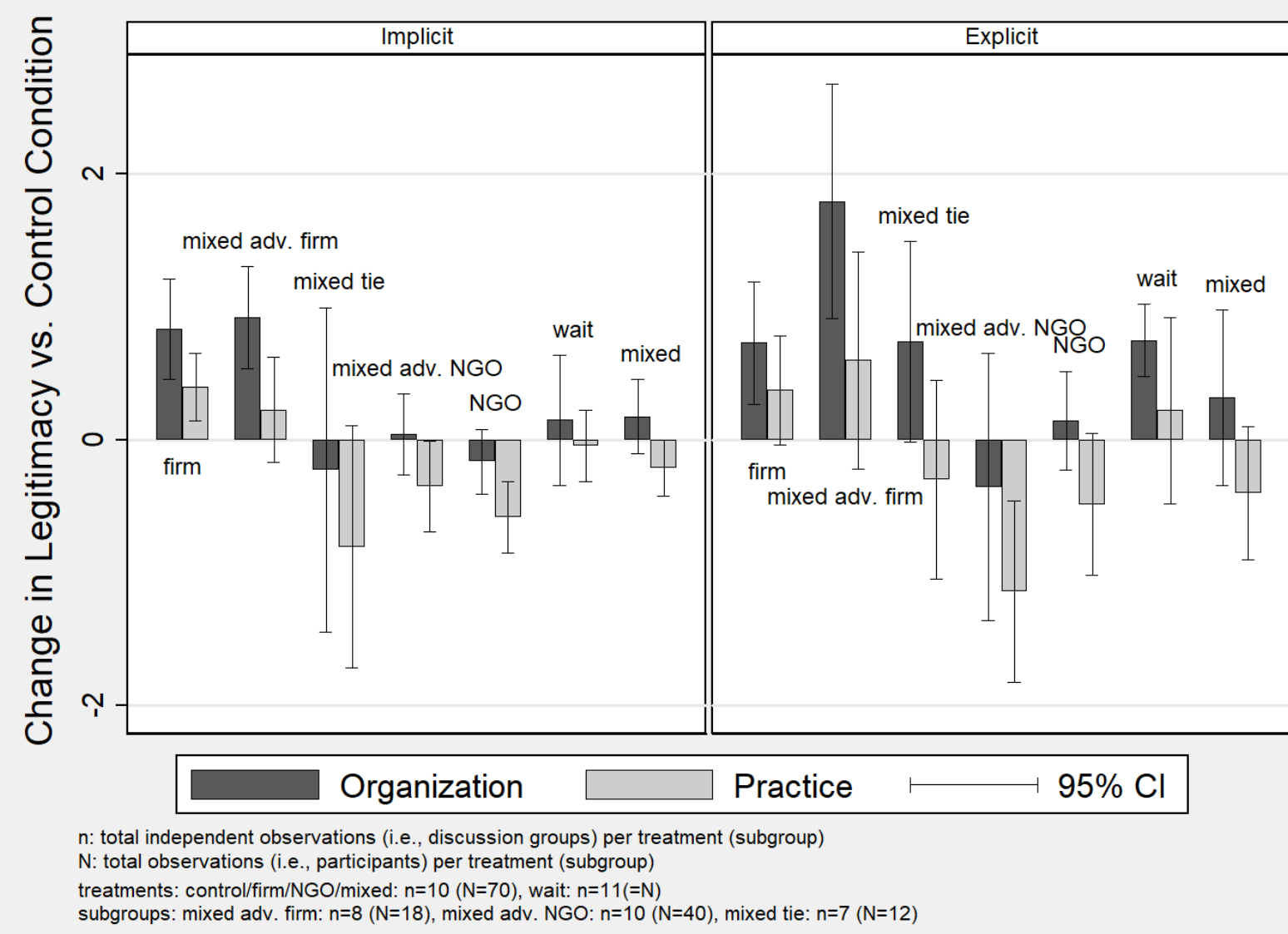

